\title{
ALGUNAS VISIONES DEL PASADO COLONIAL COMO EJE CENTRAL EN EL SURGIMIENTO DEL RELATO ÁRABE EN MARRUECOS
}

\section{Fernando Ramos López}

A poco que nos dediquemos a leer narrativa marroquí moderna dos características fundamentales nos llaman la atención: la primera es la posterioridad cronológica con la que aparecen las primeras producciones marroquíes de reconocida madurez literaria en relación a la literatura árabe oriental. Si bien la literatura neo-árabe surge en Egipto a fines del siglo XIX y principios del XX, las primeras producciones de literatura marroquí moderna de expresión árabe no aparecen hasta los años cuarenta. Las manifestaciones previas y preparatorias del renacimiento cultural árabe que se dan en Egipto e Iraq durante la primera mitad del XIX, se producen en Marruecos, excepción hecha de algunas figuras aisladas, a paso ligero durante las primeras décadas de nuestro siglo.

La causa primera de esta diferencia radica en la desconexión del resto del mundo árabe que para Marruecos supuso el hecho de quedar fuera del Imperio otomano, más exactamente fuera de la leve modificación de estereotipos cultistas que experimentarían las letras árabes en los últimos tiempos de la dominación turca y la posterior renovación, sobre todo de la prosa, que supondría el contacto con Occidente a lo largo de todo el XIX. Ello además de otras causas más inmediatas como la continuidad de la circunstancia geopolítica de relativo aislacionismo sufrido por Marruecos durante el período de Protectorado (hasta 1956), que impidió el acceso a modelos renovados; el conservadurismo islámico mantenido hasta bien avanzado el siglo, que frenó la evolución de una conciencia artística plural, o la dispersión técnica y la escasa difusión de las primeras producciones, que no acababan de alcanzar una aceptable cota de literariedad ni en sí mismas ni en comparación con el resto de las producciones árabes aparecidas con anterioridad en circunstancias semejantes.

La segunda característica fundamental de la narrativa marroquí moderna, asunto en el que vamos a centrarnos en estas páginas, es la existencia en casi todos los textos de las primeras décadas, y aún en los posteriores, de una misma temática recurrente cuyo componente esencial aparece identificado con el colonialismo en diferentes facetas y modos de expresión. Ya sea desde un punto de vista romántico-sentimental, histórico, realista, simbólico, existencialista u otros, el colonialismo está presente en casi toda la producción narrativa marroquí del siglo XX.

Ambas particularidades, que también lo son en parte de la moderna prosa árabe en general, son síntoma evidente de hasta qué punto las producciones de los narradores 
marroquíes aparecen condicionadas por las circunstancias geopolíticas y socio-culturales del país. La narrativa marroquí moderna surge en un contexto político, ideológico y cultural muy concreto: el recrudecimiento de los afanes colonialistas de los años veinte y treinta y la lucha nacional anticolonialista hasta finales de los cincuenta. En este contexto, los contenidos intelectuales franceses y españoles exportados a Marruecos no son precisamente los de vanguardia, sino más bien adaptaciones de algunas obras románticas francesas del XIX. Por su parte, el realismo y naturalismo españoles del XIX pasan por alto, ya que sólo parecen influir y tímidamente poetas como Gerardo Diego o Vicente Aleixandre. ${ }^{1}$ En este sentido, pese a la escasa actividad cultural marroquí de estos años, pronto los pioneros de la que podemos denominar "Nahda (renacimiento) marroquí" van a encontrar su orientación precisamente en oriente, en las producciones del Mašriq, ante cuyo impulso ideológico no se quedarían insensibles. De este modo, y dentro de los límites tolerados, la ideología política, religiosa y cultural que se afirmaba en el Valle del Nilo encuentra su eco en pleno desarrollo de la lucha anticolonial marroquí. Influencia determinante tendrían en estas escasas producciones marroquíes los escritos reformistas de Muhammad ${ }^{\mathrm{C}} \mathrm{Abduh}$ y los ensayos sociales de Musțafà Luṭī al-Manfalūṭ̂, además de los ecos de la lucha nacionalista de $\mathrm{Sa}^{\mathrm{c}} \mathrm{Z}$ Zaglūl, asociada en Marruecos a la del emir ${ }^{\mathrm{c}} \mathrm{Abd}$ al-Krīm.

El enfrentamiento colonizador-colonizado es en la narrativa marroquí, tanto o más que en el resto de las narrativas árabes, la constante vital que la hace surgir y la impulsa hacia su desarrollo. Este conflicto aparece reflejado de diversas maneras: recordando hazañas de caballeros de otro tiempo, alentando el heroísmo sentimental y admonitorio de los mártires contemporáneos, transmitiendo el esfuerzo inútil de un anciano por defender su mundo intacto o reflejando las angustias del que no encuentra refugio sino al margen de la realidad. Para poner de manifiesto estas particularidades de la narrativa marroquí contemporánea, nada mejor que ir directamente a los textos. Con tal objeto he seleccionado algunos fragmentos representativos en torno a los cuales podemos ver algunas de las formas en que el fenómeno colonial se refleja en las primeras manifestaciones de la narrativa marroquí, concretamente en el relato. Desde estos primeros momentos y extendiéndose hasta los años sesenta, el ensayo es la nueva forma de prosa que se convierte en el medio de expresión de numerosas ideas y asuntos de índole política, social y cultural, así como de cuestiones literarias, llegando a ser el canal de expresión más frecuente entre los intelectuales del momento. ${ }^{2}$

\footnotetext{
' Sobre esta importante cuestión mantienen plena actualidad las publicaciones siguientes: F. de Ágreda Burillo. "Encuesta sobre la literatura marroquí actual", Almenara 2 (1972) 133-165; 3 (1972) 107-145; 5-6 (1974) 305-336 (Posteriormente en Cuadernos del «Seminario de Literatura y Pensamiento Árabes» 2, I.H.A.C., Madrid 1975). Y P. Martínez Montávez. "Las relaciones literarias hispano-árabes contemporáneas. Planteamiento de la cuestión", en Literatura árabe de hoy (Madrid 1990) 15-35 (Originariamente en Estudios de Asia y África 43 (1980) 102123.

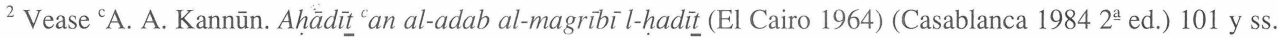
Buena muestra de la importancia que este género literario tuvo (y tiene) en el país vecino sigue siendo la amplia muestra de textos presentados en versión española en Literatura y Pensamiento marroquíes contemporáneos.
} 
Pasando por alto estas publicaciones de carácter ensayístico-retórico nos encontramos con las primeras producciones narrativas. Se trata de una serie de textos, tentativas iniciales de relato, que los intelectuales marroquíes de los años treinta y cuarenta utilizan como vehículo de expresión de la incomodidad y el desconsuelo que experimentan al encontrarse aislados del resto del mundo árabe. En este tipo de narraciones encontramos dos planteamientos: uno el romántico-sentimental y otro el histórico. Ambos son planteamientos solapados e indirectos. Dos ejemplos representativos de narraciones romántico-sentimentales son "An dahāyā 1-hubb" ("Acerca de las víctimas del amor") (1938), de Hasan al-Sabīhī, y "ㅁât al-tawb al-abiyaḍ" ("La del vestido blanco") (1939), de un autor conocido por el seudónimo Hamām, que tratan un amor ideal inalcanzable $\mathrm{y}$, técnicamente, son experimentos en los que el autor más que perseguir una unidad narrativa prefiere explicar sentimientos, y en lugar de interiorizar en ellos, se dispersa. Todas ellas son producciones iniciales de escasa trascendencia tanto para la evolución del género narrativo como para el seguimiento del tema que nos ocupa.

El planteamiento de enfoque histórico sí ofrece algunos elementos ideológicos y temáticos con sentido y finalidad determinados. Tomando la Historia como materia de narración y atendiendo a los hechos históricos en sí mismos, la narración-relato ${ }^{3}$ histórica de los años cuarenta supone la adaptación de la forma narrativa para abordar los hechos históricos y actualizarlos. Supone también el intento de imprimir un nuevo carácter al legado histórico para acercarlo a la expresión literaria moderna. Frente a la decadencia del momento histórico, el intelectual marroquí desea expresar un sentimiento entusiasta por la patria que le conduce a desenterrar a los personajes que pasaron a la Historia de Marruecos como héroes nacionales en los antiguos enfrentamientos con los cristianos del norte. El objetivo perseguido en estas obras es poner de manifiesto la confrontación existente entre la opresión a la que el pueblo es sometido por el colonizador y el deseo de libertad. Para ello el autor destaca el espíritu de lucha del marroquí y su disposición de sacrificio por la patria. Este espíritu de sacrificio aparece simbolizado en la actuación de un protagonista generalmente solitario que, a la manera de las gestas antiguas, se enfrenta valientemente con sus colonizadores. Se trata pues del tema repetido y explotado por varios de los primeros autores de reconocido éxito en la literatura neo-árabe, caso del egipcio Ŷurŷ̄ Zaydān (1861-1914) entre otros, cuya novela histórica hace frecuente referencia al tema andalusí y en ella los escritores marroquíes se ven identificados.

Las primeras narraciones de tema histórico con intención literaria e ideológica aparecen

(Madrid-Rabat 1981) «Seminario de Literatura y Pensamiento Árabes Modernos». Serie «Antologías Nacionales» III.

${ }^{3}$ Término utilizado por P. Martínez en Introducción a la Literatura árabe moderna, (Madrid 1985), p. 182, y que nosotros adoptamos como adaptación de los términos árabes "al-qișsa al-șūra", propuesto por M. al-Ṣādiq "Afīfĩ en Al-Qișsa al-magribiyya al-hadīta (Beirut 1961), pp. 18 y ss.; y "al-șüra al-qașașiyya", propuesto por A. alMadīn̄ en Fann al-qisșa al-qașīa fĭ l-Magrib. Fì l-naš' a wa-l-tațawwur wa-l-ittiŷāhāt, pp. 128 y ss. para referirse a las narraciones aparecidas en esta época y con ciertas características técnicas que las sitúan a medio camino entre las primeras manifestaciones de ficción y el relato maduro. 
publicadas en periódicos como $\mathrm{Al}-\mathrm{Wid} \bar{a} d, \mathrm{Al}-\mathrm{Sa} a^{c} \bar{a} d a$ o $\mathrm{Al}-^{c} \mathrm{Alam}$ durante los años cuarenta.

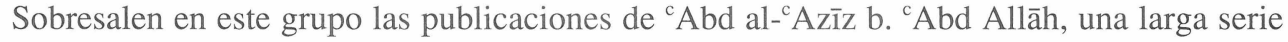
de narraciones de tema repetitivo, cuya trama suele girar en torno a una heroína en el papel de espía en medio de las luchas entre musulmanes andalusíes y cristianos, cuyas hazañas se suceden a lo largo de numerosos capítulos. "Al-Ŷasūsa al-muqanna" ("La espía enmascarada") (1948) rememora la victoria de al-Muctamid b. ${ }^{c} A b b a \bar{d}$ respaldado por los almorávides de Yūsuf b. Tāšfīn sobre el ejército de Alfonso VI (1086). A éstas se une la interesante serie de narraciones acerca de doncellas con participación heroica en la historia de Marruecos, como es el caso de "Gādat Așịla" ("La doncella se Asila") (1949), que describe la batalla del río Majāzin (1578), y otros títulos, algunos de los cuales aparecen recogidos en la posterior colección del autor aparecida en 1973 bajo el título Šaqrä' al-Rîf (La rubia del Rif). En semejante línea sobresale "Adrā' Sabta" ("La doncella de Ceuta") (1942), de ${ }^{\mathrm{C}} \mathrm{Abd}$ al-Rahmān al-Fāsī, ${ }^{4}$ en la que el conde don Julián se debate entre el orgullo de sus grandes ambiciones y el destino en su contra. Esta es una de las mejores representantes del conjunto y en ella el poder de los musulmanes se impone una vez más, aunque sea en la ficción, sobre los gentiles del norte. En el siguiente fragmento nos llama la atención la actualidad permanente del discurso desde los años cuarenta hasta nuestros días:

«El sol de poniente empezó a lanzar sus dorados rayos sobre el palacio del Conde Julián. La brisa del anochecer perfumaba la ciudad de Ceuta, la rumí, con los aromas de los arrayanes y la fragancia de las flores. Surgió la alta talla del Conde en la terraza de su gran palacio, con sus bigotes puntiagudos; dirigía su vista hacia España, la goda, su protectora, el guarda de la rumí en este castillo; hoy, sin embargo, la vista de España produce dolor en su corazón y agita sus pensamientos. La historia de don Rodrigo 'el usurpador' había turbado su espíritu: aquel joven ligero que ocupó por fuerza el trono de Witiza y se metió en pasiones y amoríos, sin tener en cuenta a aquellos árabes que sometieron la mayor parte de Îfrīqīyā, y se apostaron en la costa esperando la oportunidad de ocupar el castillo. [...]

El Conde se quedó de pie, derrotado, envuelto por las sombras, y se puso a recitar como una plegaria:

¡Misericordia, Dios mío!

Sólo confío en tu justa voluntad.

Dios misericordioso, no permitas que tus criaturas

corrompan la tierra y no se corrijan.

¡Arabes, emisarios del bien y de la paz!

¡Venid y purificad esta tierra de los gusanos de la

corrupción!

¡Levantaos para alimentar a un pueblo al que

despojaron de todos sus bienes!

¡Levantaos y proteged los derechos del hombre!

\footnotetext{
${ }^{4}$ Al-Widād 142 (1942), p. 6. Posteriormente en 'A. al-R. al-Fāsī. 'Ammī Būšnāq (Rabat 1972), pp. 113-126. Y también en 'A al-R. al-Fāsī. Qiṣaṣ wa-Ṣuwar (Casablanca 1985), pp. 91-100.
} 
En aquel momento llegaron ruidos y alborotos que hicieron incorporarse al Conde y que inundaron los pasillos del dormido palacio. Sobrecogido, gritó en un quejido:

-¿Qué pasa?

Pero su voz no pasó de la puerta.

-¿Dónde está la guardia?

Nadie le escuchó.

- ¿Qué ruido es ese?

"Son los hombres de Țāriq b. Ziyād que han cercado el palacio, señor Conde".»5

Como es sabido, en el Mašriq, las tendencias del relato árabe moderno han ido evolucionando paralelamente al devenir de las principales realidades socio-políticas de los años treinta y cuarenta. Partiendo de esta base, podemos distinguir, en principio, dos fuerzas políticas: una, el régimen establecido representado por gobiernos que rigen a lo largo del período apartados de las demandas populares de independencia y cambio social y comprometidos con las fuerzas coloniales; y dos, el movimiento nacionalista o patriótico representado por un partido mayoritario, dinámico y reformista que lucha por la independencia política, económica y cultural. Igualmente, estas dos realidades políticas conllevan, en el Mašriq, dos modos diferentes de concebir la identidad nacional, que se corresponden con dos tendencias principales en el relato árabe de los años treinta, cuarenta y cincuenta. La primera, la narrativa romántica y costumbrista de Mahmūd Taymūr y la sentimental de Mahmūu Kāmil, inspirada en la nueva clase media; la segunda, el relato realista elaborado de Yahyà Haqqī, exploración en la esencia de las diferentes facetas de la identidad nacional y articulación de sus aspiraciones. Por su parte, los escritores marroquíes se convierten durante los años cuarenta y cincuenta en receptores de gran cantidad de obras procedentes del Mašriq, principalmente de Egipto, obras pertenecientes a distintos géneros, tendencias y estilos, así como representantes de diferentes visiones y concepciones de la sociedad y la identidad nacional de rápidas y sucesivas transformaciones. Atraídos por ellas, sobre todo por las obras maestras de los autores mencionados, los narradores marroquíes van a intentar asimilarlas aportando como resultado numerosos ejemplos de narraciones en las que observamos el aglutinamiento y la amalgama de estas tendencias y concepciones.

Los ejemplos que citamos a continuación aparecen agrupados junto a otros por un denominador común cuyo eje se centra directa y concretamente en la lucha entre colonizador y colonizado, y entre los componentes injusticia y paz. Cronológicamente, estas narraciones se enmarcan en los momentos previos a la independencia de Marruecos, tiempos de concienciación, fervor y lucha generalizada contra el colonizador. Y ese mismo es el ambiente narrativo de estas composiciones, presentadas de modo descriptivo y con una intención de análisis que sitúa al escritor en una posición determinada en el movimiento de resistencia en busca de su responsabilidad y su función en la lucha por la independencia.

\footnotetext{
${ }^{5}$ Trad. M. 'Īsà y F. de Ágreda, en Literatura y Pensamiento..., p. 149 y 152.
} 
Se trata de obras inspiradas en el heroísmo y el romanticismo surgidos en la moderna literatura árabe acompañando los acontecimientos en semejantes momentos históricos y en cada país.

Muhammad al-Jadir al-Raysūn̄̄, hombre destacado por su participación en el movimiento nacionalista, es uno de los pioneros del relato marroquí y principal representante de la "tendencia" romántica de los cuarenta y cincuenta, si bien más que tendencia diríamos que se trata de una actitud de "tono melodramático", como la califica el crítico marroquí Naŷîb al- ${ }^{c} \bar{U}_{f i 1}{ }^{6}$, en los inicios de este género. El contenido fundamental es el amor y los sentimientos dramáticos que conducen al desencanto. En conjunto, su colección $\operatorname{Rabi}^{c}$ al-hayāt (La primavera de la vida) (1957) es una obra de lucha y oposición a la causa colonialista. Tanto los acontecimientos y detalles históricos que afluyen entrecortados, como los diálogos, están dispuestos para describir la realidad con el objetivo de concienciar al individuo frente a la sociedad. Partiendo de un hecho histórico concreto, al-Raysūnī crea una realidad hipotética, una trama muy simple con algún componente de intriga en la que a veces y arbitrariamante aparece un escueto diálogo y en la que los acontecimientos no siempre se suceden con un enlace narrativo homogéneo. "Ardunā 1cazizza" ("Nuestra amada tierra") es un ejemplo representativo del conjunto. Localizado en una aldea de ambiente bucólico en el corazón del Atlas, un joven conoce al cabo de los años cuál fue el destino de sacrificio por la patria que antaño corriera su padre. El motivo desencadenante de la trama es el deseo de hacer realidad el honor de seguir los pasos de su padre y la obligación moral y patriótica de defender a su Rey, Muhammad V, que acaba de ser destronado por los colonialistas:

$[\ldots] \ll$ Poco después salió seguido de su madre que le habló de corazón. Lloraba atormentada y le requirió con voz contrita: "¡Anda hijo, quédate a mi lado!" El contestó: "La llamada de la Patria me reclama. Tendré que marchar lejos, madre, para participar con mis hermanos en la batalla: la batalla contra el enemigo usurpador, madre, la batalla por el Rey, por nuestra tierra..."

Volvió Ben 'Isà al huerto, miró la tierra y la pequeña y creciente vegetación lleno de esperanza. Luego siguió sus pasos y, al pasar por el arroyo, se fijó en un pequeño anillo de oro caído junto a la lisa roca. Caminaba implorando: "¡Nuestra tierra, nuesta amada tierra, lo eres todo para nosotros!"

Aquello era el comienzo del sacrificio y de la lucha por la libertad!» ${ }^{7}$

Llama la atención en esta narración la prioridad que el autor confiere a la idea sobre el texto, al mensaje por encima de la literariedad. Mensaje que se presenta arropado por un argumento muy simple y una trama reducida a un espacio muy limitado, pero envueltos en una atmósfera romántica, casi teatral, con un cierto aire de narración popular caballeresca incluso. Otro hecho histórico es el desencadenante de la narración "Hubb wa-īmān" ("Amor

\footnotetext{
${ }^{6}$ N. al-'Ūfī. Muqārabat al-wāqi' fì l-qișsa al-qașìra al-magribiyya. Min al-ta'sīs ilà l-taŷnīs. (Casablanca 1987), p. 109.

${ }^{7}$ Trad. F. de Ágreda, en Literatura y Pensamiento..., p. 220 y 221.
} 
y fe"), incluida en la misma colección. En este caso se trata del atentado perpetrado el 11 de septiembre de 1953 contra Mūlāy b. 'Arafa, sucesor de Muḥammad V, durante los días de destierro del monarca, por ${ }^{\mathrm{c}}$ Allāl b. ${ }^{\mathrm{c}}$ Abd Allāh, pintor de la construcción que se convierte así en símbolo de la desesperación y la cólera de todo el pueblo, y que "pasaría" a la literatura en esta narración, cuyo objetivo último es mover al lector y suscitar una reforma social firme.

Postura opuesta a la de Raysūnī es la de ${ }^{c} A b d$ al-Maŷ̄i b. Ŷallūn. Su colección $W a \bar{a} d \bar{l}$ l-dimā' (El valle ensangrentado) (Cairo 1947), ${ }^{8}$ es el principal exponente de la narrativa marroquí de resistencia. Buena parte de la narrativa de ${ }^{c} A b d$ al-Maŷīd b. Ŷallūn se enraíza en la actualidad histórica de Marruecos vivida por el autor. Sin embargo, este escritor, más que hacia una temática basada en la polémica agresiva, se inclina hacia el uso de un lenguaje alegórico, apto para diluir los motivos recriminatorios en los que se basan sus relatos. En opinión de U. Rizzitano, la moderación en el ánimo del narrador coloca la técnica narrativa de este autor en una cota comparable a la mejor producción narrativa francesa o egipcia, de la que ha sabido emanciparse para conquistar la independencia de forma y contenido. ${ }^{9}$ Supone esta afirmación del arabista italiano el reconocimiento de la presencia en esta colección de algunos pasajes de un nivel de literariedad no alcanzado hasta el momento en la narrativa árabe en Marruecos, y tampoco por muchas de las obras que aparecerán posteriormente. Historia del pasado inspirada en el presente, o historia del presente inspirada en el pasado, "Wādī l-dimā’", es una alegoría de la historia de los habitantes de una aldea que sueñan con un futuro de justicia:

«No volvimos a poder conciliar el sueño tras la décima noche, cuando ya todo en la tienda estaba mojado; así que nos sentamos a conversar. Aquella noche nos parecía más tenebrosa que las noches pasadas; nuestros ojos no percibían, en medio de las sombras, más que una débil luz en dirección a la tienda de los cobradores de impuestos. Mientras tanto, nuestra conversación, como venía ocurriendo desde hacía diez días, saltaba de un tema a otro. Hasta que un pastor beduino nos entretuvo con un tema nuevo, jy qué tema! Señalando con la mano la luz del relámpago, nos dijo: "Mirad, ¿veis aquel valle? Os hablaré acerca de él. Es el valle ensangrentado".

Todo a nuestro alrededor engendraba el terror en las almas, y por ello aquel nombre suscitaba en nuestros corazones un significado formidable. Mientras hablaba el cielo se abría, y a la luz de los relámpagos veíamos aquel valle lejano como si nunca antes lo hubiéramos visto, ladera terrible que terminaba al pie de un viejo monte de quebrantos, lleno de grandes rocas dispersas.

"¿El valle ensangrentado?" -preguntamos al beduino al unísono.

Y dijo: "Sí, el valle ensangrentado. Antiguamente se alzaba aquí una aldea regida por un gobernante tirano cuya vida estuvo repleta de sangre, afrentas y robos, y era este valle el matadero en el que sacrificaba a sus víctimas, que se convirtió como resultado en un lago de

\footnotetext{
${ }^{8}$ Rabat? 1957. Túnez 1958. Casablanca 1989.

9 "Il "Racconto" (qișa) nella narrativa araba contemporanea del Marocco", en Atti del Terzo Congresso di Studi Arabi e Islamici. (Ravello, 1-6 settembre, 1966) (Napoles 1967), p. 587.
} 
sangre. La depravación de aquel tirano le llevó a erigir palacios y jardines alrededor del lago y lo convirtió en paraíso de sus pasiones desenfrenadas, continuamente abastecido de la sangre de sus víctimas. Pero una noche, estando el tirano en una de sus veladas al borde del rojo lago, bebiendo vino y galanteando con las mujeres, se levantó embriagado a mirarse sobre la superficie del lago a la luz de la luna. Pero algo terrible sucedió: Tan pronto llegó a la orilla miles de manos surgieron de las entrañas del valle, las manos de sus víctimas, y lo arrastraron entre gritos hasta el fondo, donde el tirano desapareció para siempre".

Suspiramos profundamente e intentamos reír para convencernos a nosotros mismos de que la sugestión en que nos encontrábamos se había desvanecido. Pero uno de nosotros se volvió a la luz del relámpago y vio al jefe de los cobradores arrastrándose por el camino hacia el valle, lo señaló en silencio, lo vimos y nos intercambiamos las miradas.

El beduino [...] exclamó: "¿No os lo dije? Ved que las historias de nuestros antepasados siempre son verdaderas, que el valle se venga arrastrando al injusto hacia él. No volveréis a pagar impuestos a partir de hoy [...]".

Todos los cobradores de impuestos caminaban hacia el valle para reunirse con sus víctimas». (1989: 9-13).

En una especie de visión telescópica, el plano real de la metáfora viene dado por la descripción de una aldea de campesinos pobres, azotados por los cobradores de impuestos del Protectorado francés; es el presente de la narración. El plano metafórico está constituido por una historia fantástica, narrada por uno de los personajes, cuyo protagonista es una antigua aldea sita en ese mismo lugar y regida antaño por un opresor, la sangre de cuyas víctimas, arrojadas al valle, formó un lago del que una noche salieron brazos que lo arrastraron hasta el fondo. Ambos planos se unen al final de la narración cuando una fuerte ráfaga de viento arrastra al grupo de cobradores de impuestos al lago. Como queda ilustrado en el fragmento anterior, podemos constatar un notable cambio en la concepción del lenguaje literario de Ibn Ŷallūn respecto de los autores marroquíes anteriores. En su obra narrativa ya no vemos el estilo prosístico de objetivo didáctico y doctrinal, caracterizado por la rigidez de las estructuras y las connotaciones semánticas fáciles. Las narraciones de esta colección son los primeros ejemplos de narrativa breve marroquí en los que observamos un lenguaje literario moderno, de estructuras más flexibles y contenidos semánticos elaborados que nos brindan numerosos ejemplos de asociaciones e imágenes visuales y auditivas con las que este autor logra una considerable expresividad al objeto de transmitir su mensaje al lector.

Una de las narraciones-relato más impactantes en el conjunto de la obra de ${ }^{\mathrm{c}} \mathrm{Abd}$ alMaŷìd b. Ŷallūn es "Sā'id al-asmāk" ("El pescador"), narración de corte romántico en tanto que el protagonista busca en la muerte la evasión de la imposibilidad de realizar su único deseo en la vida. ${ }^{\mathrm{c}} \mathrm{Abbās}$ es un pescador que tras haber pasado la vida en el mar le llega la noticia de que ese mar tiene dueños y que no podrá volver a pescar más en él. Al rebelarse ante la injusticia, su barca es destruida y él encarcelado. Liberado, adopta la costumbre de visitar durante la noche la playa y las barcas de los franceses. Un amanecer, el anciano pescador decide hacerse a la mar en medio de la tormenta entre viento y olas, prefiriendo la muerte antes que vivir en una tierra a la que ya no pertenece. La atmósfera 
creada en esta narración en torno al personaje no es la de rebelión cruda, ni la del propósito de venganza, sino simplemente la de la amargura del afligido por el doloroso encuentro con una realidad a la que no se rinde.

Por su parte, "c $\bar{A}$ 'iša", en la misma colección, es la historia de una heroína solitaria al estilo de las narraciones fantásticas de tradición popular. ' $\overline{\mathrm{A}}$ 'iša, como una Juana de Arco marroquí, hija del caudillo de una aldea cercana a Marrakech arrasada por el colonizador, es la única superviviente de la tragedia. Ella sola, símbolo de libertad, hace frente a los ocupantes desde la fortaleza de la aldea, y mucho tiempo después, los habitantes de la zona seguirán recordando su hazaña al oír de vez en cuando los ecos de los disparos de su fusil. Así pues, estas narraciones nos describen enfrentamientos más o menos violentos entre colonizador y colonizado; en el primero residen los valores inhumanos e injustos, mientras que en el segundo residen los valores humanos y de justicia.

El colonialismo introduce un sistema político, militar y policial, así como económico y social ante el cual la industria tradicional no puede competir, produciéndose como resultado la emigración rural a las ciudades. Ello conduce a una grave problemática social que es el tema fundamental de numerosas narraciones de los años cuarenta y cincuenta. Como telón de fondo se mantienen las figuras del colonizado y el colonizador envueltos en un mecanismo de lucha. Sin embargo, mientras que en las narraciones anteriores los personajes reflejan un carácter luchador y heroico, en los ejemplos que mencionamos a continuación son pasivos y derrotistas. Los héroes legendarios son ahora personajes de corte realista e individuos en crisis. Esto supone una importante transformación en la evolución del personaje narrativo, que se aleja del arquetipo inalterable y se acerca progresivamente al retrato vivo y complejo, tanto en sus componentes históricos como artísticos. La defensa de la identidad adopta aspectos más complicados. La figura del colonizador deja de ser un elemento físico y pasa a ser una fuerza oculta y dominadora, y el colonizado adopta la actitud de víctima afectada por la incertidumbre. Técnicamente, estos textos aparecen como una especie de "noticias narradas" o "relatos de noticias" en los que el contenido es más importante que el modo de decirlo. ${ }^{10}$ En la narración-relato de tendencia social observamos por primera vez la aparición de elementos de carácter realista, entendiendo por tal no la expresión de la reacción de una clase media en defensa de las clases bajas o de la igualdad social, sino la simple adopción por parte de los autores de ciertos elementos de carácter realista, presentes en las obras orientales, para expresar un sentimiento colectivo de adversidad y una tendencia natural de lucha contra la injusticia social ${ }^{11}$. Como ya ocurrió antes en el Mašriq, el tema central es el conflicto entre lo antiguo y lo moderno. Dos buenas muestras representativas son "cAmmī Būšnāq" ("El tío Būšnāq") (1941), ${ }^{12}$ de

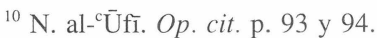

11 Véase S. Hafez. "The Modern Arabic Short Story" en M. M. Badawi (Ed.) Modern Arabic Literature (Cambridge 1992), especialmente, pp. 302-304. La concepción del "realismo" en la narrativa marroquí en particular merece tratarse detenidamente, y esperamos volver sobre este tema en una próxima ocasión.

${ }^{12}$ Al-Widād 91-92 (1941). Posteriormente: Al-Turiyā (marzo 1946). 'A al-R. al-Fāsī. 'Ammī Būšnāq (1972), pp. 3-14, y Qisas wa-Suwar (1985), pp. 7-14.
} 
"Abd al-Rahmān al-Fāsī, y "Maŷdūb Zalāg" ("El lunático de Zalāg"), incluida en la tardía colección Fās fì sab qișaș (Fez en siete cuentos) (1968), de Ahmad Bannānī.

El tío Būšnāq es almuédano y mozo de café en Fez. Contrario a todo lo que sea nuevo y atento a una severa conciencia religiosa, este personaje representa una generación de marroquíes en camino de extinción que se mantiene aferrada a los comportamientos del pasado y a su mentalidad. En esta narración el autor muestra, paralelamente al paso del tiempo, la indignación que siente el anciano ante la invasión de novedades y modas europeizantes. A diferencia de los ejemplos anteriormente mencionados, este texto ofrece una coherencia narrativa más conseguida. Sin embargo, este logro no aparece acompañado a igual nivel por el análisis de la transformación social experimentada por la generación a la que pertenece el protagonista, ni por la descripción del mismo:

«Si te volvías a mirarlo mientras caminabas, veías a un anciano esbelto, pálido, con la cabeza y el bigote canos, las arrugas de su rostro revelaban los sesenta y, a pesar de ello, tenía el pecho erguido y la espalda fuerte, no era flaco ni débil. Te saltaba a la vista su espesa barba blanca y zigzagueante, que, sobre su pecho, daba la impresión de ondas de luz. Luego aquel turbante, ¡qué turbante!, una caperuza roja -fácil de decir pero pesada de llevar- rodeada de tantas brazas de burdo lino que no dejaba ver de su color rojo intenso más que los bordes que le cubrían las sienes. El anciano, además, lo había rematado con un talismán hiyazí, que añadía a su peso el peso de la historia y que era el centro de sus veladas y el pretexto para iniciar sus charlas.[...]

¡Había que verlo hablar de su época pasada con palabras entrecortadas por los ayes e interrumpidas por los suspiros! Tajante y seguro de lo que decía, podía darte mil pruebas de que en estos tiempos ya no existía la baraca, de que Dios había privado a toda la gente de virtud y de que, sin duda alguna, la Hora estaba próxima, ¿no era acaso un síntoma ver a las mujeres engalanarse y contonearse vestidas con chilabas de hombre? ¿No era una señal fumar y cortarse el pelo?, ¿no lo era ver a los hombres con la barba afeitada y sin bigote?» ${ }^{13}$

Al final del relato, se produce la transformación del personaje de "acusador" en "acusado", capturado por el tiempo, cuando los vecinos descubren que su hija fuma cigarillos. El desenlace introduce un componente de ironía, de "mala pasada que le juega la vida al anciano", con el que cAbd al-Raḥmān al-Fāsī convierte esta narración en algo más que una simple narración descriptiva o de exposición subjetiva del escritor.

"Maŷdūb Zalāg", de Ahmad Bannānī, es la denuncia de un fenómeno del que el tío Riḍwān es testigo: el hecho de que la gente, de la noche a la mañana, empieza a sobrevalorar todo lo nuevo y a rechazar todo lo que suponga sumisión al pasado. En contra de ello, el protagonista es el representante de un mundo de profundas raíces, con su propio modo de pensar y actuar, símbolo de una generación a caballo entre dos formas de sentir y dos civilizaciones. El tío Riḍwān se considera a sí mismo el último superviviente de una generación. Es un personaje del pasado con sus tradiciones y modos de vida al que se le

\footnotetext{
${ }^{13}$ Trad. B. Molina. Antología de relatos marroquíes. (Murcia 1990), pp. 30, 32 y 33.
} 
impone la tecnología del colonizador en forma de radio ${ }^{14}$ y lo vuelve loco:

«El tío Riḍwān no tenía familia ni hogar; vivía solo en un enorme cementerio en medio de la ciudad, rodeado de casas por todas partes, y cuando anochecía, se retiraba a un rincón para dormir, sin más compañía que los muertos de las sepulturas. Su mayor afición era cultivar plantas entre las tumbas: había logrado transformar el cementerio en un hermoso jardín, con su tierra plagada de flores y sus muros repletos de jazmines. Solía vender semillas, flores, arrayanes y todo tipo de hierbas en su puerta.[...]

Un día me vino un conserje que trabajaba con los franceses para que le remendara los zapatos. Se sentó a esperar a mi lado y el tío Riḍwān lo vio. Y, como si de un botín se tratara, vino hacia él corriendo al tiempo que le decía: "Por Dios te pido que me cuentes; tú trabajas con los franceses, vives con ellos y conoces sus asuntos. ¿Acaso te han informado del secreto de esa máquina diabólica que ha vuelto mi entendimiento confuso y mi pensamiento ausente, pues pretenden que trae los sonidos de los rincones del mundo, cercanos o lejanos?" [...]

Yo, que andaba distraído en mi trabajo, no llegué a enterarme de la conversación, pero sé que, desde entonces, el tío Riḍwān comenzó a ausentarse durante el día; sólo por la tarde, tras la oración, lo veía pasar delante de mí y entrar en el cementerio presuroso y abstraído, sin dirigirme saludo alguno.

Un día llegó hasta aquí con unas botellas viejas entre los brazos. "¡Lo he logrado. Por fin he conseguido encerrar las voces en estas botellas!"

Quise preguntarle por su logro, por las voces, por las botellas y por el significado de todo aquello, pero se alejó velozmente hacia el cementerio».

Más tarde el tío Rị̣wān explica su locura:

«Cuando me encontré con aquel conserje [...] se me ocurrió la idea de libraros de aquellas voces que volaban por el cielo; por eso subía al monte Zalag para capturarlas y meterlas en las botellas que me veías transportar. No creas que lo tuve fácil. Sólo el amor a Dios me ayudó a superar la fatiga y el cansancio del esfuerzo. ¡Qué trabajo me costaba capturar una nube de voz!

Pero cierto día, una gran ráfaga de viento irrumpió; las botellas caían desde la terraza del cementerio, se lanzaban y estrellaban contra las tumbas rompiéndose en mil pedazos. Sus voces prisioneras se liberaron fundiéndose sus chillidos con el estruendo de la tempestad.

Y ocurrió que, por una vez en su vida, el destino quiso satisfacer sus deseos, pues tal vez el azar provocó el corte de la luz de aquella noche, sin que lámparas ni radios pudieran encenderse ni gritar. De esta forma, un inmenso silencio reinó durante el entierro, y allí quedó, descansando eternamente, junto a la misericordia de Dios». (1968: 76 y ss.)

Con esta narración, incluida en el amplio muestrario de testimonios del pasado y sus

\footnotetext{
${ }^{14}$ Tema recurrente, la radio, como símbolo de modernidad y de occidentalización cuya programación amenaza con ocupar el lugar de las tertulias y las narraciones de los ancianos. Entre otros ejemplos: Naŷî̉ Maḥūz. Zuqāq almidāqq (1947).
} 
símbolos que constituye la colección Fās fī sab qiṣaș, Aḥmad Bannānī aporta un elemento novedoso al presentar el conflicto entre lo nuevo y lo antiguo no como un simple fenómeno, sino como un desafío al que ineludiblemente debe someterse el protagonista y, con él, la sociedad entera. De modo que el conflicto adquiere una doble dimensión: la concreta, de enfrentamiento entre dos civilizaciones, y la universal, de lucha entre la vida y la muerte.

Durante los años sesenta, tras la independencia, los textos publicados son ejemplos de una tímida evolución artística y un entramado narrativo que intenta imitar la manera de la narrativa egipcia de entre-guerras. En ellos se observa un tono más reflexivo y a la vez más radical. El tema del colonialismo se plantea en dos vertientes: la cuestión nacional y la cuestión de la tierra. Ambas vertientes aparecen bien representadas en muchos ejemplos de los que destacamos la colección Māta qarìr al- ${ }^{c} a y n$ (Murió tranquilo) (1965), de 'Abd alKarīm Gallāb. Estos textos son el reflejo de la permanencia de la subordinación tras la independencia y de la continuidad de la relación explotador-explotado propia del neocolonialismo. El contenido de resistencia y de combate aparece sobre estas fechas en torno a la idea de una juventud perdida en la lucha por una autodeterminación que no acaba de llegar. La narración-relato homónima, "Māta qarīr al- ${ }^{c} a y n "$, es una muestra cargada de heroísmo, en la que la palabra, los pensamientos y buena parte de las posturas ideológicas de Muhammad, su protagonista, parecen anticipar el programa según el cual serán llamados a actuar los marroquíes apenas el país salga de la fase revolucionaria a la fase constructiva. En este sentido, podemos considerar esta colección como una invitación a meditar sobre la función exhortativa de esta narrativa teñida de una moral de recriminación e invectiva contra el pasado colonial. Los personajes de esta colección se desenvuelven en el clima de un pasado reciente de experiencias negativas. Con esta obra Gallāb denuncia a las nuevas generaciones las consecuencias del Protectorado a través de las vicisitudes de algunas de sus víctimas. En "Hāris al-matḥaf" ("El guarda del museo"), el autor invita a una meditación sobre la diferencia que existe entre quienes participan con su muerte en la causa común y quienes maduran la conciencia lejos del enfrentamiento directo, inmersos en su propia cotidianeidad. El tío al-Ṭā' $i^{c}$, un pequeño funcionario "condenado" durante treinta años a ocupar el puesto de guarda de un museo, es testigo durante los años de revolución del ir y venir de los visitantes empeñados en la organización de una revuelta de la que él no soporta sustraerse. Ante su mundo de inmovilidad, una mañana, anticipándose a la rebelión, se lanza contra las estatuas y las hace pedazos para sentirse finalmente liberado. Mientras unos testigos lo consideran un loco, otros lo consideran símbolo de desesperación y emancipación.

La confiscación de tierras es el tema central de "Ibn al-maŷhūl" ("El desconocido"), título incluido en la misma colección de Gallāb. ${ }^{c}$ Abd al-Rahmān es el pequeño propietario desposeído y encarcelado por resistirse a las exigencias de los nuevos dueños, y que, una vez liberado, se encuentra imposibilitado de insertarse en la sociedad en la que había ocupado una posición de prestigio. La pérdida de la tierra se identifica con la pérdida de la libertad, y, paradójicamente, cuando ésta última es recuperada, se convierte en sinónimo de esclavitud. Gallāb aborda el tema de la tierra desde una posición ideológica liberal- 
conservadora, ${ }^{15}$ y lo propone como una crisis individual del personaje creado. Sus personajes, conscientes de la sociedad y ante cuya injusticia buscan una solución personal, se mueven en un mundo envuelto por una aureola de desconsuelo y depresión, y en ella asumen sus destinos en una lucha desigual que les anula toda capacidad de reacción. Gallāb no se limita a poner de relieve las dos figuras opuestas del explotador y el explotado, sino que prefiere hacer abstracción del asunto, extrayendo las preocupaciones, los efectos, la ternura o el sentimiento individualizado en cada personaje:

«Toda esa tierra que dejaron mis abuelos con el esfuerzo de sus músculos y que regaron con el sudor de sus cuerpos para que fueran abundantes los frutos y madurasen, y sobre ella han arremetido las entrañas de la codicia... Toda esa tierra a caído en manos de una panda de ladrones que..., que no voy a nombrar». (1965: 60).

En esta colección se incorpora igualmente la instantánea del "color local", en cuya investigación y explotación se empeñarán muchas producciones posteriores con el fin de descubrir el espíritu del pueblo, de sus acciones y reacciones de la vida diaria. A lo largo de los sesenta y setenta, Gallāb continúa publicando relatos insistiendo en la misma temática. Estos relatos serán recogidos en la colección Al-Ard habībatì (La tierra, amada mía) (1974) y en ellos, al igual que en todas las publicaciones del autor, se pone de manifiesto su adscripción ideológica que le conduce a crear un ambiente un tanto artificial en sus narraciones, sobre todo por el elevado nivel de lenguaje que pone en boca de sus personajes.

La densidad de "Hadiya marfūda" ("Un regalo rechazado") (1966), tanto respecto del contenido como respecto de la estructura narrativa, nos impulsa a considerar desde este momento a Muhammad Barrāda como un narrador de calidad. Enmarcado en el denominado "realismo crítico" de los sesenta, el personaje en torno al cual gira este relato es un colectivo completo en sí mismo, un grupo compacto constituido por individuos perfectamente identificados cada uno de ellos en su propio espacio y al mismo tiempo formando un solo cuerpo en un único espacio global. Son los habitantes de la aldea llamada al-Rummānī. Tres son los principales: al-Hāšimī, un campesino al que hace veinte años le fue expropiada su tierra y ahora trabaja en ella para el colono cargando carros de tierra que posteriormente extiende en otro terreno. Abā l-Fātmī, el carnicero, que se caracteriza por su capacidad para divulgar las noticias. Y el sobrino de al-Hāšimī, que trabaja con su tío. Y solidarios con ellos el resto de los habitantes de la aldea. Frente a todos ellos, aparece otro grupo de personajes que participan indirectamente y que está formado por el colono Monsieur Roni y el caíd, además del ministro de agricultura y su esposa. Una mañana alHāšimī llega al mercado y oye rumores que por fin Abā l-Fāṭmī le confirma: con la independencia ha llegado una ley por la que se van a devolver todas las tierras confiscadas.

${ }^{15}$ Véase J. A. Pacheco Paniagua. "cAbd al-Karīm Gallāb y la literatura política en el Magreb contemporáneo" Philologia Hispalensis VI, I (1991), pp. 153-161. 
Con dudas y esperanzas al-Hāšimī va a informarse al caíd pero éste no consigue desengañarlo. Abā 1-Fātmīi le sugiere hacer un regalo al ministro, con el que seguro intercedería por él. Todo el pueblo apoya la idea. A partir de este momento la acción del relato se traslada a la ciudad. Al-Hāšimī, su sobrino y el buey que llevan de regalo interrumpen el tráfico de las calles y un guardia les indica el camino a la casa del ministro, en cuya puerta sacrifican el animal. La esposa, horrorizada, llama a la policía. Finalmente, ante la dificultad que entraña trasladar al buey muerto y consciente del fracaso del intento, al-Hāšimī se resuelve a malvender la carne por kilos para recuperar el dinero.

El tema central es la tierra, pero en segundo plano se plantean otros temas como la ocultación inicial de la situación de al-Hāšimī, el carácter resignado de los habitantes de la aldea, el silencio en el que se han habituado a vivir y que envuelve el ambiente, el despertar de un rencor latente contra el colono francés o la permanencia de éste en sus tierras hoy como ayer. El relato está repleto de simbologías: en la primera parte, que se desarrolla en el espacio rural, aparecen símbolos de carácter humano o abstracto, como la opresión y la resignación, la rudeza, la ingenuidad y el esfuerzo. En el espacio urbano, los símbolos son físicos, como el policía, el tráfico, el guarda de la villa, la esposa del ministro, la policía; o ideales, como la indolencia de la mujer o la figura del ministro, ausente e inalcanzable. Por ello, y por otros elementos de carácter técnico, no estimamos exagerado considerar "Hadiya marfūda" como el relato de la época, el relato paradigma en el que se concentran los temas más tratados así como los logros alcanzados hasta el momento por los narradores marroquíes, a partir del cual empezamos a respirar "aires nuevos" en la narrativa breve de este país.

El relato de los años sesenta y setenta continúa marcado por una visión social que se desprende de los acontecimientos políticos. Se produce la escisión entre dos bloques de población: uno, el constituido por una clase elevada de procedencia burguesa, de tendencia conservadora, que anuncia nuevos valores políticos capaces de mejorar la situación social y establecer las bases de una posterior política democrática. Esta clase centraliza los sectores comercial y privado en las ciudades, y produce una cultura conservadora y sincrética entre el legado árabo-islámico y el liberalismo europeo. El otro bloque está formado por obreros, pequeños comerciantes, profesionales, funcionarios medios y estudiantes, capas sociales progresistas que aspiran a una liberalización económica, social y cultural. De este bloque emerge a lo largo de estos años una "clase media" con actitudes de "pequeña burguesía" que va a desempeñar un importante papel en los ámbitos político e ideológico. De esta clase surgen los nuevos géneros literarios, el teatro y el relato, como medio de expresión de sus preocupaciones.

El sector agrario, eje de la economía marroquí, se degrada y es la principal fuente de parados, que se establecen en los suburbios creados junto a los centros industriales de las principales ciudades. A ellos se une la población nómada que se ve indirectamente afectada. En la ciudad, la explosión de la natalidad está protagonizada por este segundo bloque de población. Además de la emigración del medio rural al urbano, se produce otra hacia el extranjero. Mientras que la inflación afecta a los productos de primera necesidad, los levantamientos entre la población rural y las huelgas entre la población activa urbana crea 
enfrentamientos violentos. Podemos empezar a hablar aquí de la aparición en Marruecos de la tercera realidad socio-política, paralela a una tercera gran tendencia del relato árabe moderno, impulsada por el movimiento popular representado por grupos de estudiantes e intelectuales de izquierdas que rechazan el poder establecido, aunque, al mismo tiempo, se muestran incapaces de conciliar el amplio abanico de ideales en un frente común. Ellos van a ser los pioneros de esta nueva fase en la evolución de la narrativa marroquí contemporánea hacia un realismo crítico que pronto se transformará en un realismo nuevo, manifestaciones literarias reflejo de la fragmentada realidad socio-política que las inspira.

El intelectual marroquí progresista vive los acontecimientos con impaciencia, incertidumbre y desencanto. Ahmad al-Sattātīi se expresaba así en 1964: "Los intelectuales pensaban que tras la independencia serían llamados a desempeñar su papel natural de dirección y aceptación de la responsabilidad [...]. Sin embargo, la amarga decepción experimentada tras descubrir las dificultades y obstáculos que impedían la realización de sus aspiraciones y deseos ha creado en ellos diversas reacciones y diferentes tipos de comportamientos". ${ }^{16}$

A partir de estos momentos el relato aspira a conviertese en el portavoz literario "oficial" de la pequeña burguesía, será la expresión de las preocupaciones y problemas de esta clase y llevará a cabo una importante función en la modernización cultural del país en tanto que género literario más empleado.

En el contexto de búsqueda de la propia identidad nacional el tema del colonialismo se mantiene presente, como una pesadilla que nunca termina. Por lo que respecta a la narrativa breve, el tema pasa de ser casi único en la producción de las primeras décadas, a formar parte del conjunto de temas de los años setenta y ochenta como un elemento temático más, integrante de la sociedad y el medio vital marroquíes descrito en los relatos; un conflicto más entre todos los problemas económicos, sociales, familiares e individuales.

Sobre la figura del "extranjero" recae un resentimiento íntimo y retenido, pocas veces olvidado, que aflora de nuevo con virulencia cuando se trata de representantes de las instituciones coloniales existentes aún en Marruecos. En los relatos de los años setenta y ochenta, el colonialismo aparece como causa de todos los males, como factor de cambio negativo en la sociedad que impone necesidades como el consumo capitalista o el deterioro en las estructuras sociales urbanas y como símbolo de una huella indeleble que mancha la identidad y coharta la libertad del marroquí. Los ejemplos son muy numerosos y aparecen diseminados por toda la producción narrativa de estos últimos años. En ellos sobresale este tema y otros más como la ciudad, los personajes urbanos, la emigración o el papel asignado a la mujer en la sociedad marroquí actual. Temas, éstos, de interés en la cada vez más sobresaliente narrativa marroquí y sobre los que esperamos volver en otra ocasión. 
